\title{
Synthesis and Study of Azo-Dye Compounds: Various Molecular Stackings from Different Polarities of the Molecules
}

\author{
by Long-Li Lai*, Feng-Ya Su, Yu-Jen Lin, Chia-Husan Ho, and Eshin Wang \\ Department of Applied Chemistry, National Chi Nan University, Puli, Taiwan 545, R.O.C. \\ (Tel.: 886-49-2910960 4975; fax: 886-49-2917956; e-mail: lilai@ncnu.edu.tw) \\ and Chen-Hsiung Hung \\ Department of Chemistry, National Changhua University of Education, Changhua, Taiwan 500, R.O.C. \\ and Yi-Hung Liu and Yu Wang \\ Instrumentation Center and Department of Chemistry, National Taiwan University, Taipei, Taiwan 106, R.O.C. \\ One non-F-containing and two F-containing azo-dye compounds were prepared to investigate their \\ molecular stackings by X-ray crystallography. Introduction of the F-atom into the aromatic moiety of azo-dye \\ compounds leads to a variation of the charge distribution and consequently to different molecular stackings. \\ Accordingly, the mesogenic behaviors in the solid state are different.
}

Introduction. - Recently, the supramolecular aggregate by molecular self-assembly has been an important issue in the field of structural chemistry [1]. In addition to electrostatic interaction, noncovalent forces also play a significant role in determination of the structural stacking and properties of molecules [2]. The interaction between the aromatic moiety of the molecules is found to be critical for the molecular packing in crystallization [3], and furthermore the stability and phase behavior of mesogenic molecules have been reported to arise therefrom [4]. Particularly, the electronegativity of $\mathrm{H}$ - and F-atoms are obviously different (Pauling scale: $\mathrm{H} 2.1$, $\mathrm{F}$ 4.0), and, thus, the replacement of the $\mathrm{H}$ - by the F-atom in aromatic moiety may result in significant variation of molecular polarity. Although many studies have disclosed the molecular packings with replacement of $\mathrm{H}$ - by F-atom, most of them were focused only on small molecules, in which the shape and size of the molecules are effective on the molecular stacking during the crystallization. Therefore, the polarity of the molecules does not have significant influence in the crystal packing [5]. However, the molecular size of liquid crystals is rather big (molecular length ca. 20-40 $\mathrm{A}$ ) and its polarity may significantly influence the molecular packing in the crystal engineering. Particularly, it has been shown that pure benzene adopts an edge-to-face structure in the solid state [6], and the structure of benzene/hexafluorobenzene materials at low temperatures consists of face-to-face stacks of alternative molecular arrangement [7]. Coates et al., thus, successfully utilized this phenyl/perfluorophenyl-stacking interaction to prepare olefinic compounds by photopolymerization [8]. Thus, the replacement of $\mathrm{H}$ - by $\mathrm{F}$-atoms in the aromatic moiety does, to some extent, cause different molecular stacking in the solid state. However, the perfluorophenyl derivative is not inexpensive. 
We, thus, introduced a single F-atom into our azo dye system and expected similar results, i.e., different molecular stackings between fluoro and nonfluoro liquid crystals. As the $\mathrm{N}=\mathrm{N}$ moiety of liquid crystals seems to preferably form smectic phase [9], we applied this model to change the molecular stacking and consequently modify the mesogenic behaviors of the azo-dye molecules systematically in the future. Now, we report our primary results.

Results and Discussion. - Compounds 1a-1c were synthesized according to the Scheme. Reaction of diazonium salt $\mathbf{2}$ with phenol, 2-fluorophenol, and 3-fluorophenol, respectively, in $\mathrm{EtOH}$ gave the corresponding azo compounds $\mathbf{3 a - 3 b}$ in $c a$. $50 \%$ yield, which were further treated with decanoyl chloride in the presence of $\mathrm{Et}_{3} \mathrm{~N}$ in $\mathrm{CH}_{2} \mathrm{Cl}_{2}$ to yield the desired products $\mathbf{1 a - 1 c}$, respectively. These compounds have similar molecular compositions except that an aromatic $\mathrm{H}$-atom in $\mathbf{3 a}$ was replaced by a Fatom at different positions to give $\mathbf{1 b}$ and 1c. The packing diagrams for the intermolecular interaction of compounds $\mathbf{1 a - 1 c}$ in the solid state, obtained from crystallographic studies, are shown in Figs. 1-3, respectively. In Fig. 1, each molecule of $\mathbf{1 a}$ is regularly arranged head-to-head or head-to-tail to adjacent molecules in the same or different layers. Based on the crystallographic studies, the molecules are found to be parallel to the neighboring molecules in the same layer (e.g., molecules a1 and a2 in layer A), and the distances between two corresponding atoms in the same layers (e.g., $\mathrm{Na}$ and $\mathrm{Nb}$ and $\mathrm{Ca}$ and $\mathrm{Cb}$ ) are all ca. 5.57 $\AA$. The molecules in different layers are also approximately parallel to others, and the closest distance between two adjacent layers (not including the $\mathrm{H}$-atoms) is $3.36 \AA$, which is, for example, found for $\mathrm{C}(1)-\mathrm{O}(1)$ and $\mathrm{C}(2)-\mathrm{O}(2)$ between $\mathrm{B}$ and $\mathrm{E}$ layers. The distances between $\mathrm{O}(1) \cdots \mathrm{H}($ at $\mathrm{C}(1))$ and $\mathrm{O}(2) \cdots \mathrm{H}($ at $\mathrm{C}(2))$ are found to be both $2.58 \AA$, which are shorter than the sum of the Van der Waals radii of $\mathrm{H}$ - and $\mathrm{O}$-atoms (Bondi radii: $\mathrm{H}$ 1.20, F 1.47, O 1.52) [10a], and the $\mathrm{H}$-bond interaction arising therefrom should influence the crystallizing process. The distances of the $\mathrm{O}(3) \cdots \mathrm{H}$ (at $\mathrm{C}(3))$ and $\mathrm{O}(4) \cdots \mathrm{H}($ at $\mathrm{C}(4))$ are both $3.0 \AA$, which are in the range of normal H-bond lengths [10b].

As shown in Fig. 2, the molecules of $\mathbf{1 b}$ are regularly arranged similar to those of compound 1a. The distances between two corresponding atoms of two parallel molecules in the same layer (not including the H-atoms) as described for Fig. 1 are all ca. $6.13 \AA$. The closest distance between two adjacent layers (not including the $\mathrm{H}$ atoms) is $3.62 \AA$, which is, e.g., found for $\mathrm{C}(1)-\mathrm{O}(1)$ and $\mathrm{C}(2)-\mathrm{O}(2)$ between the layers $\mathrm{A}^{\prime}$ and $\mathrm{B}^{\prime}$. The distance of $\mathrm{O}(1) \cdots \mathrm{H}$ (at $\left.\mathrm{C}(5)\right)$ is $2.40 \AA$, which is shorter than the sum of the Van der Waals radii of $\mathrm{H}$ - and $\mathrm{O}$-atoms. The distances of $\mathrm{O}(3) \cdots \mathrm{H}$ (at $\mathrm{C}(3)), \mathrm{O}(4) \cdots \mathrm{H}$ (at $\mathrm{C}(3))$, and $\mathrm{F}(1) \cdots \mathrm{H}$ (at $\mathrm{C}(4)$ ) are $2.95,3.05$, and $3.11 \AA$, respectively, which are in the range of normal H-bond lengths.

The molecules of 1c are regularly arranged as shown in Fig. 3. The distances between two corresponding atoms of two parallel molecules in the same layer (not including the $\mathrm{H}$-atoms) as described for Fig. 1 are all ca. $5.36 \AA$. The closest distance between two adjacent layers (not including the $\mathrm{H}$-atoms) is $3.01 \AA$, which is, e.g., found for $\mathrm{F}(1)-\mathrm{C}(1)$ between the layers $\mathrm{A}^{\prime \prime}$ and $\mathrm{B}^{\prime \prime}$, as well as $\mathrm{F}(2)-\mathrm{C}(2)$ between the layers $\mathrm{B}^{\prime \prime}$ and $\mathrm{E}^{\prime \prime}$. The distances $\mathrm{F}(1) \cdots \mathrm{H}($ at $\mathrm{C}(3))$ and $\mathrm{F}(1) \cdots \mathrm{H}$ (at $\left.\mathrm{C}(4)\right)$ are 2.73 and $2.76 \AA$, respectively. The distances of $\mathrm{O}(2) \cdots \mathrm{H}($ at $\mathrm{C}(5))$ and $\mathrm{O}(3) \cdots \mathrm{H}($ at $\mathrm{C}(6))$ are both $2.57 \AA$, and the distance $\mathrm{O}(4) \cdots \mathrm{H}($ at $\mathrm{C}(7))$ is $2.58 \AA$. It is interesting to note that 

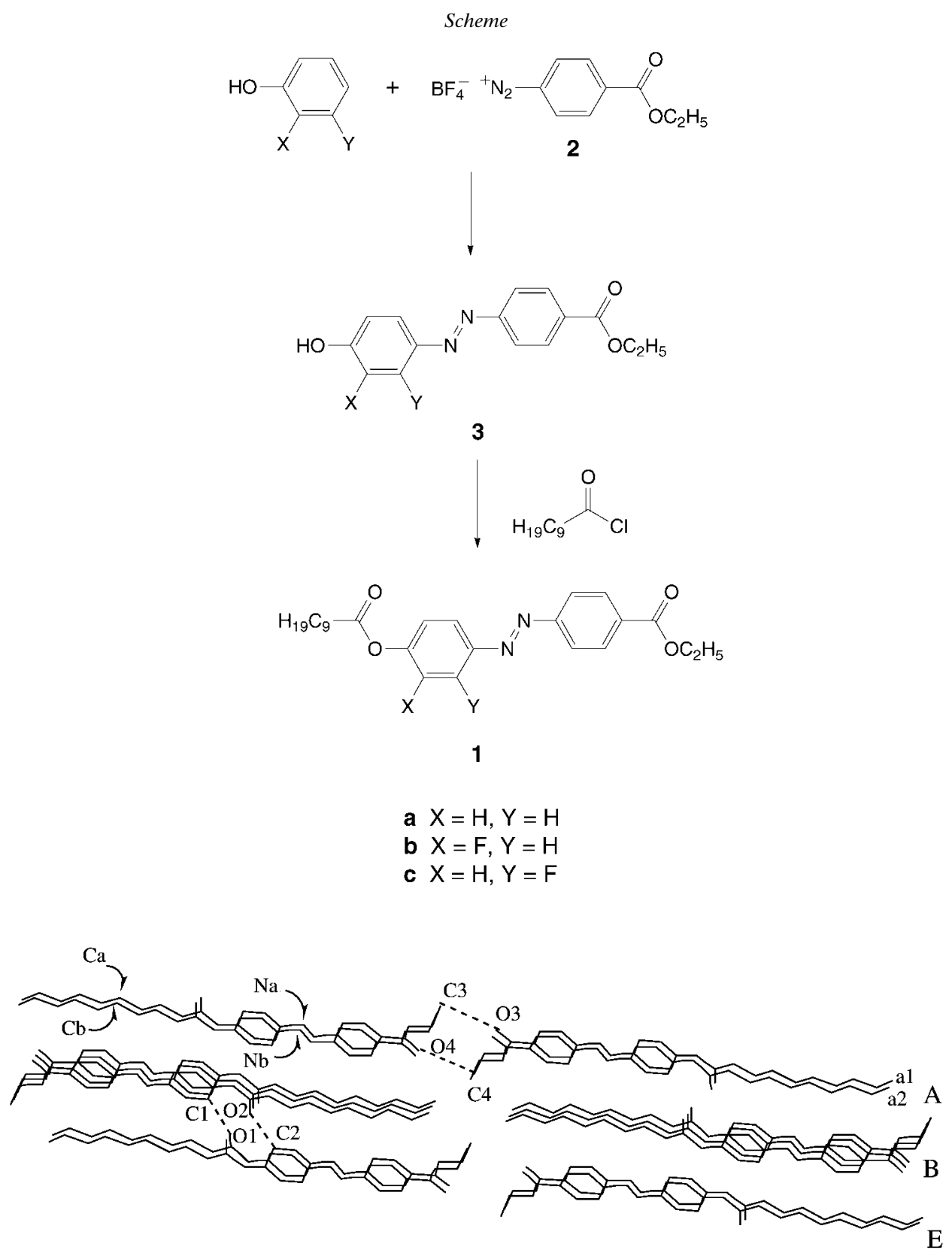

Fig. 1. The molecular packing of compound $\mathbf{1 a}$ in the solid state. The $\mathrm{H}$-atoms are omitted for clarity.

the $\mathrm{H}$-bonding interaction in compound $\mathbf{1} \mathbf{c}$ is much stronger than that of $\mathbf{1 a}$ and $\mathbf{1 b}$. The $\mathrm{H} \cdots \mathrm{F}$ and $\mathrm{H} \cdots \mathrm{O}$ distances of compound $\mathbf{1 c}$ are approximately equal to or shorter than the sum of the Van der Waals radii of $\mathrm{H}$ - and F-atoms (or O-atom). 


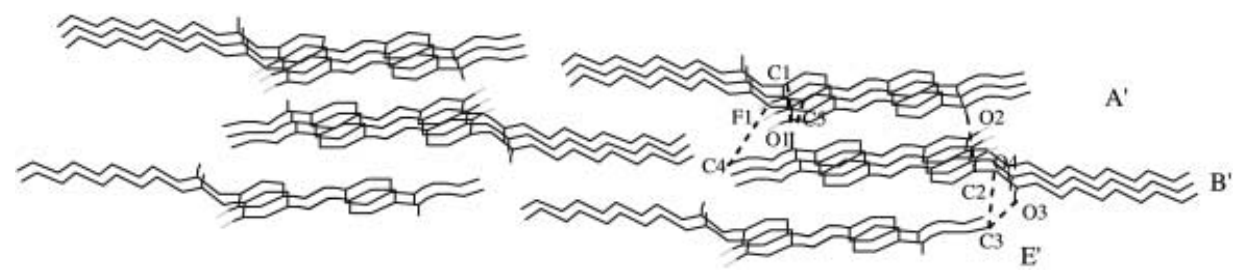

Fig. 2. The molecular packing of compound $\mathbf{1 b}$ in the solid state. The $\mathrm{H}$-atoms are omitted for clarity.

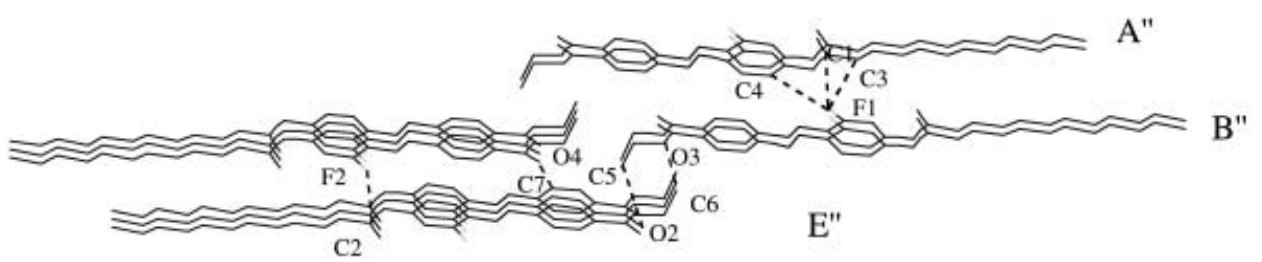

Fig. 3. The molecular packing of compound $\mathbf{1 c}$ in the solid state. The H-atoms are omitted for clarity.

Apparently, the driving force of the molecular stacking of compounds $\mathbf{1 a - 1 c}$ all arise from the mutual attraction of polar functional groups together with the interaction of the H-bonds. However, introduction of a single F-atom into the aromatic moieties of 1b and 1c changes the contribution of molecular polarity, and, thus, the mutual attraction between aromatic moieties for $\mathbf{1 b}$ and $\mathbf{1 c}$ are more effective in the solid state when compared with $\mathbf{3 a}^{1}$ ). Consequently, various molecular stacking in the aromatic moieties was obtained and different mesogenic properties of compounds $\mathbf{1 a}-\mathbf{1 c}$ were observed during the thermal process ${ }^{2}$ ). Compound 1a shows a SmB phase in the range of $40-95.2^{\circ}$ in the heating process and $88.4-40^{\circ}$ in the cooling process. Compound $\mathbf{1 b}$ is monotropic and shows a nematic phase $\left(50.3-43.5^{\circ}\right)$ in the cooling process. Only compound 1c shows a highly ordered SmX phase in the heating $\left(73.0-71.8^{\circ}\right)$ and cooling process $\left(73.0-71.8^{\circ}\right)$ probably because of stronger intermolecular H-bonding interaction.

In summary, three azo-dye compounds were prepared and studied by X-ray crystallography. The consistent results imply that variation of the polarity of the liquidcrystalline molecules effectively change the way of molecular stacking in the solid state, and may provide a guide to modify the mesogenic behaviors of the liquid-crystalline molecules.

1) Each single molecule of compounds 1a-1c was optimized by semi-empirical calculations in the gas phase. The conformation of these molecules are found quite similar, and the details of the study will be published elsewhere.

2) The SmB phase of compound 1a was characterized by polarizing optical microscopy in a stepped-drop texture, and further confirmed with the hexagonal arrangement of the molecules with no tilt angle from the study of powder-XRD and single-crystal structure determination. The nematic phase of compound $\mathbf{1 b}$ was characterized in a schlieren texture. The mesogenic behaviors were recorded in the second heating or cooling by $D S C-6$ at a rate of $10 \% \mathrm{~min}$. 


\section{Experimental Part}

General. Chemicals used were commercially available from ACROS. The mesogenic behaviors and phase transitions were characterized by polarizing optical microscopy and differential scanning calorimetry (PerkinElmer DSC 6). FT-IR Spectra [cm $\left.{ }^{-1}\right]$ : Perkin Elmer $R X-I .{ }^{1} \mathrm{H}-\mathrm{NMR}$ : Varian 300 FT-NMR spectrometer; ${ }^{13} \mathrm{C}-\mathrm{NMR}$ spectra: Bruker 200 FT-NMR spectrometer; $\delta$ in ppm; $J$ values in Hz. HR-EI-MS: VG70-250; $70 \mathrm{eV}$.

Synthesis of Compounds 1a-1c. A soln. of $\mathrm{PhOH}(1.88 \mathrm{~g}, 20 \mathrm{mmol})$ and $\mathrm{KOH}(1.12 \mathrm{~g}, 20 \mathrm{mmol})$ in $\mathrm{H}_{2} \mathrm{O}$ $(20 \mathrm{ml})$ was added to a soln. of [4-(ethoxycarbonyl)benzene]diazonium tetrafluoroborate $(\mathbf{1} ; 5.17 \mathrm{~g})$ in EtOH. The soln. was then stirred at r.t. for $2 \mathrm{~h}$. A suitable amount of aq. $\mathrm{HCl}$ was added to maintain the resulting soln. slightly acidic ( $\mathrm{pH} 5-6)$. The product precipitated was filtered off and purified by chromatography to give $2.45 \mathrm{~g}(45.4 \%)$ of ethyl 4-[(4-hydroxyphenyl)diazenyl]benzoate (3a). Similarly, ethyl 4-[(3-fluoro-4-hydroxyphenyl)diazenyl]benzoate (3b) and ethyl 4-[(2-fluoro-4-hydroxyphenyl)diazenyl]benzoate (3c) were obtained in $57.7 \%$ (3.3 g) and 48.5\% (2.79 g) yields, resp. Reaction of compounds $3 \mathbf{a}-\mathbf{3 c}$ ( $2 \mathrm{mmol})$ with decanoyl chloride ( $2 \mathrm{mmol}$ ) in $\mathrm{CH}_{2} \mathrm{Cl}_{2}$ with excess $\mathrm{Et}_{3} \mathrm{~N}$ yielded the desired corresponding products $\mathbf{1 a}-\mathbf{1 c}$ in $\mathrm{ca}$. $85 \%$ yield after normal workup.

Data of Ethyl 4-\{[4-(Decanoyloxy)phenyl]diazenyl\}benzoate (1a): 84.7\% (0.72 g). IR: 3130, 2955, 2921, 2849, 2363, 1942, 1753, 1713, 1601, 1581, 1491, 1466, 1413. ${ }^{1} \mathrm{H}-\mathrm{NMR}\left(\mathrm{CDCl}_{3}\right): 0.85(t, J=5.4, \mathrm{Me}) ; 1.26-1.53$ $\left(m, 6 \mathrm{CH}_{2}, \mathrm{Me}\right) ; 1.69-1.78\left(m, \mathrm{CH}_{2}\right) ; 2.57\left(t, J=7.8, \mathrm{CH}_{2}\right) ; 4.40\left(q, J=7.2, \mathrm{CH}_{2}\right) ; 7.24\left(A A^{\prime} B B^{\prime}, J=8.7\right.$, 2 arom. H); $7.91\left(A A^{\prime} B B^{\prime}, J=8.7,2\right.$ arom. H); $7.97\left(A A^{\prime} B B^{\prime}, J=8.7,2\right.$ arom. H); $8.17\left(A A^{\prime} B B^{\prime}, J=8.7\right.$, 2 arom. H). ${ }^{13} \mathrm{C}-\mathrm{NMR}\left(\mathrm{CDCl}_{3}\right): 171.84 ; 165.98(\mathrm{C}=\mathrm{O}) ; 154.97 ; 153.32 ; 150.06 ; 132.19 ; 130.53 ; 124.33 ; 122.57$; $122.31 ; 61.22 ; 34.41 ; 31.83 ; 29.38 ; 29.23 ; 29.08 ; 24.86 ; 22.63 ; 14.30 ; 14.07$. HR-MS: $424.2361\left(\mathrm{C}_{25} \mathrm{H}_{32} \mathrm{~N}_{2} \mathrm{O}_{4} ;\right.$ calc. 424.2362).

Data of Ethyl 4-\{[4-(Decanoyloxy)-3-fluorophenyl]diazenyl\}benzoate (1b): 73.6\% (0.65 g). IR: 2956, 2917, 2350, 1750, 1714, 1601, 1598, 1507, 1493, 1490, 1428, 1410. ${ }^{1} \mathrm{H}-\mathrm{NMR}\left(\mathrm{CDCl}_{3}\right): 0.87(t, J=5.4, \mathrm{Me}), 1.26-1.54$ $\left(m, 6 \mathrm{CH}_{2} ; \mathrm{Me}\right) ; 1.69-1.80\left(m, \mathrm{CH}_{2}\right) ; 2.62\left(t, J=7.5, \mathrm{CH}_{2}\right) ; 4.40\left(q, J=7.2, \mathrm{CH}_{2}\right) ; 7.30(t, J=7.5,1$ arom. H $) ; 7.74$ $(2 d, J=9.0,2.4,1$ arom. $\mathrm{H}) ; 7.81(2 d, J=9.0,2.4,1$ arom. $\mathrm{H}) ; 7.92\left(A A^{\prime} B B^{\prime}, J=8.7,2\right.$ arom. $\left.\mathrm{H}\right) ; 8.17$ $\left(A A^{\prime} B B^{\prime}, J=8.7,2\right.$ arom. H). ${ }^{13} \mathrm{C}-\mathrm{NMR}\left(\mathrm{CDCl}_{3}\right): 170.87 ; 165.87(\mathrm{C}=\mathrm{O}) ; 156.21 ; 154.62 ; 152.87 ; 150.86$; $140.94 ; 140.76 ; 132.59 ; 130.56 ; 124.03 ; 122.74 ; 121.57 ; 109.34 ; 109.07 ; 61.27 ; 33.89 ; 31.82 ; 29.36 ; 29.20 ; 28.98$; $24.84 ; 22.63 ; 14.28 ; 14.06$. HR-MS: $442.2268\left(\mathrm{C}_{25} \mathrm{H}_{31} \mathrm{FN}_{2} \mathrm{O}_{4}\right.$; calc. 442.2268).

Data of Ethyl 4-\{[4-(Decanoyloxy)-2-fluorophenyl]diazenyl\}benzoate (1c): 68.2\% (0.60 g). IR: 3117, 2956, 2920, 2850, 1758, 1714, 1610, 1587, 1485, 1468, 1427, 1412. ${ }^{1} \mathrm{H}-\mathrm{NMR}\left(\mathrm{CDCl}_{3}\right): 0.87(t, J=5.4, \mathrm{Me}) ; 1.22-1.55$ $\left(m, 6 \mathrm{CH}_{2}, \mathrm{Me}\right) ; 1.63-1.80\left(m, \mathrm{CH}_{2}\right) ; 2.57\left(t, J=7.5, \mathrm{CH}_{2}\right) ; 4.40\left(q, J=7.2, \mathrm{CH}_{2}\right) ; 6.96(2 d, J=9.0,2.1$, 1 arom. $\mathrm{H}) ; 7.12(2 d, J=10.8,2.1,1$ arom. $\mathrm{H}) ; 7.81\left(t, J=8.7,1\right.$ arom. H); $7.95\left(A A^{\prime} B B^{\prime}, J=8.7,2\right.$ arom. $\left.\mathrm{H}\right) ; 8.18$ $\left(A A^{\prime} B B^{\prime}, J=8.7,2\right.$ arom. H). ${ }^{13} \mathrm{C}-\mathrm{NMR}\left(\mathrm{CDCl}_{3}\right): 171.35 ; 165.91(\mathrm{C}=\mathrm{O}) ; 162.24 ; 158.78 ; 155.06 ; 154.25 ; 154.11$; $138.28 ; 138.19 ; 132.55 ; 130.54 ; 122.84 ; 118.71 ; 117.82 ; 111.11 ; 110.80 ; 61.26 ; 34.34 ; 31.82 ; 29.36 ; 29.21 ; 29.03$; $24.76 ; 22.63 ; 14.29 ; 14.06$. HR-MS: $442.2267\left(\mathrm{C}_{25} \mathrm{H}_{31} \mathrm{FN}_{2} \mathrm{O}_{4}\right.$; calc. 442.2268).

$X$-Ray Crystal-Structure Analysis. Crystals of compounds $\mathbf{1 a}-\mathbf{1 c}$ were grown from $\mathrm{CH}_{2} \mathrm{Cl}_{2} /$ hexane $1: 1$ at r.t. Single crystal of suitable quality was mounted on a glass fiber and used for measurement of precise cell constants and intensity data collection. Diffraction measurement was made on a Siemens SMART 1K CCD diffractometer with graphite-monochromated $\operatorname{Mo} K_{\alpha}$ radiation $(\lambda=0.71073 \AA)$. No significant decay was observed during the data collection. Data were processed on a PC with SHELXTL software package [13]. The structures of 1a-1c were solved by direct methods and refined by full-matrix least-squares on $F^{2}$ value. All non-H-atoms were refined anisotropically. The $\mathrm{H}$-atoms were fixed at calculated positions and refined using a riding model. Other data for compounds $\mathbf{1 a}-\mathbf{1 c}$ were as follows.

Compound 1a: $\mathrm{C}_{25} \mathrm{H}_{32} \mathrm{~N}_{2} \mathrm{O}_{4}, P \overline{1}$, triclinic, $a=5.5711(6), b=8.4652(10), c=26.459(3) \AA, \alpha=94.993(2), \beta=$ 92.682(2), $\gamma=105.334(2)^{\circ}, V=1195.6 \AA^{3}, Z=2, \theta=1.55-27.55^{\circ}$, data collection at $293 \mathrm{~K}$, reflections measured $=14191$, reflections used $=5462\left(\left(R_{\text {int }}\right)=(0.0593)\right), R=0.0655$.

Compound 1b: $\mathrm{C}_{25} \mathrm{H}_{31} \mathrm{FN}_{2} \mathrm{O}_{4}, P \overline{1}$, triclinic, $a=6.1291(7), b=8.1812(9), c=25.910(3) \AA$, $\alpha=83.859(2), \beta=$ $87.415(2), \gamma=70.006(2)^{\circ}, V=1213.9 \AA^{3}, Z=2, \theta=1.58-27.52^{\circ}$, data collection at $293 \mathrm{~K}$, reflections measured $=14215$, reflections used $=5494\left(\left(R_{\text {int }}\right)=(0.0573)\right), R=0.0473$.

Compound 1c: $\mathrm{C}_{25} \mathrm{H}_{31} \mathrm{FN}_{2} \mathrm{O}_{4}, P \overline{1}$, triclinic, $a=5.3563(9), b=6.3360(11), c=37.519(6) \AA, \alpha=87.162(3)$, $\beta=87.465(3), \gamma=77.650(2)^{\circ}, V=1241.6 \AA^{3}, Z=2, \theta=1.63-24.99^{\circ}$, data collection at $150 \mathrm{~K}$, reflections measured $=7219$, reflections used $=3984\left(\left(R_{\text {int }}\right)=(0.0400)\right), R=0.0817$. Crystallographic data for the compounds $1 \mathbf{a}-\mathbf{1 c}$ reported in this paper have been deposited with the Cambridge Crystallographic Data Centre as supplementary publication No. CCDC-163831,163832, and 17380, resp. Copies of the data can be obtained free 
of charge on application to CCDC, 12 Union Road, Cambridge CB2, 1EZ, UK (fax: + 44(1223)-336-033; e-mail: deposit@ccdc.cam.ac.uk).

We thank the National Chi Nan University and the National Science Council (NSC 90-2113-M-260-002) for financial support. The National Center of High-Performing Computing and the Institute of Chemistry, Academia Sinica are also highly appreciated for providing the Beilstein database system as well as the most helpful library service.

\section{REFERENCES}

[1] a) J.-M. Lehn, 'Supramolecular Chemistry', VCH, Weinheim, 1995; b) A. D. Hamilton, 'Perspectives in Supramolecular Chemistry', John Wiley \& Sons, 1996.

[2] a) C. A. Hunter, Angew. Chem., Int. Ed. 1993, 32, 1584; b) C. A. Hunter, Chem. Soc. Rev. 1994, 23, 101.

[3] a) G. R. Desiraju, 'Crystal Engineering: The Design of Organic Solids', Elsevier, New York, 1989; b) G. R. Desiraju, Chem. Commun. 1997, 1475.

[4] a) K. M. Lee, C. K. Lee, I. J. B. Lin, Angew. Chem., Int. Ed. 1997, 36, 1850; b) J. Chang, J. S. Moore, J. Am. Chem. Soc. 1994, 116, 2655.;

[5] A. Nangia, New. J. Chem. 2000, 24, 1049.

[6] E. G. Cox, D. W. J. Cruickshank, J. A. S. Smith, Proc. R. Soc., London, Ser. A. 1958, $247,1$.

[7] J. H. Williams, J. K. Cockcroft, A. N. Fitch, Angew. Chem., Int. Ed. 1992, 31, 1850.

[8] G. W. Coates, A. R. Dunn, L. M. Henling, J. W. Ziller, E. B. Lobkovsky, R. H. Grubbs, J. Am. Chem. Soc. 1998, 120,3641

[9] a) L. L. Lai, H.-C. Lin, Liq. Cryst. 2000, 27, 707; b) L. L. Lai, E. Wang, L. J. Lee, J. J. Chen, D. W. Yang, Liq. Cryst. 2001, 28, 157; c) L. L. Lai, L. J. Lee, E. Wang, F. Y. Su, Liq. Cryst. 2001, 28, 381; d) L. L. Lai, L. J. Lee, G. H. Lee, Y. Wang, K. L. Lu, S. J. Lee, Liq. Cryst. 2001, 28, 1513; e) L. L. Lai, E. Wang, Helv. Chim. Acta 2001, $84,3581$.

[10] a) A. Bondi, J. Phys. Chem. 1964, 68, 441; b) F. H. Allen, J. M. P. Lommerse, V. J. Hoy, J. A. K. Howard, G. R. Desiraju, Acta Crystallgr., Sect. B 1996, 52, 734 .

[11] G. M. Sheldrick, SHELXTL version 5.03, Siemens Analytical X-Ray Instruments Inc. Madison, Wisconsin, 1994.

Received December 31, 2001 